\title{
Physical and Psychological Health Conditions of Older Adults Classified as Gardeners or Nongardeners
}

\author{
Sin-Ae Park \\ Department of Horticulture, Forestry, \& Recreation Resources, Kansas State \\ University, 3738 Throckmorton Hall, Manhattan, KS 66506
}

Candice A. Shoemaker ${ }^{1}$

Department of Horticulture, Forestry, \& Recreation Resources, Community Health Institute, and Center on Aging, Kansas State University, 2021 Throckmorton Hall, Manhattan, KS 66506

\author{
Mark D. Haub \\ Department of Human Nutrition and Center on Aging, Kansas State \\ University, 127 Justin Hall, Manhattan, KS 66506
}

Additional index words. CHAMPS questionnaire, SF-36, hand function, bone mineral density, human issues in horticulture

\begin{abstract}
The objective of this study was to compare the physical and psychological health conditions and leisure-time activities, particularly physical activities (PAs), of older gardeners and nongardeners. Fifty-three older adults were recruited from the community of Manhattan, KS. Three groups were classified based on results from the Community Healthy Activities Model Program for Seniors questionnaire: active gardeners $(n=11)$ classified as gardeners that met the Centers for Disease Control and Prevention's (CDC) PA recommendation through gardening; gardeners $(n=14)$ classified as gardeners that did not meet the CDC's $P A$ recommendation through gardening; and nongardeners $(n=$ 28). Overall physical and mental health conditions were determined with the Short-Form 36 Health Survey (SF-36), hand function (hand strength and pinch force) was determined by dynamometers, and bone mineral density (BMD) was determined by dual-energy $x$ ray absorptiometry. Active gardeners were significantly different from gardeners and nongardeners in physical health $(P \leq 0.05)$ on SF-36. There were no differences in mental health among the three groups, but all groups had scores higher than the U.S. general population. Active gardeners + gardeners had greater hand strength and pinch force than nongardeners. There was no difference in BMD among the groups, but all subjects had higher scores than the standard BMD value for their age. The only significant difference of caloric expenditure in leisure-time PAs among the groups was gardening $(P<0.001)$. In conclusion, gardening can be a useful strategy to meet the CDC's PA recommendation. In addition to the health benefits linked to regular $P A$, this study showed that gardening promotes hand strength, pinch force, and overall physical health.
\end{abstract}

Regular physical activity (PA) contributes to the prevention and reduction of chronic diseases associated with aging and can help maintain independent living [American College of Sports Medicine (ACSM), 1998; Galloway and Jok1, 2000]. Health benefits from regular PA include reduction in the risk of coronary heart disease, hypertension, type 2 diabetes, osteoporosis, ischemic stroke, selected cancers, anxiety, and depression

\footnotetext{
Received for publication 12 Sept. 2008. Accepted for publication 9 Oct. 2008.

This research was funded through awards from the Kansas State University Center on Aging and the NSF ADVANCE program of Kansas State University. Contribution no. 08-326-J of the Kansas Agricultural Experiment Station, Manhattan.

${ }^{1}$ To whom reprint requests should be addressed; e-mail cshoemak@ksu.edu
}

(ACSM, 1993, 2004; Hui and Rubenstein, 2006; Lee et al., 1991; Powell et al., 1987). Physical activity also increases fitness level, muscle strength, aerobic capacity, balance, and bone mineral density (BMD) (ACSM, 1998; DiPietro, 2001; U.S. Department of Health and Human Services, 1996). To maintain or improve health, the Centers for Disease Control and Prevention (CDC) and ACSM recommend at least 30 min of moderate-intensity PA on most days of the week (at least 150 min of moderate intensity PA per week) (Nelson et al., 2007; Pate et al., 1995).

Gardening is a popular leisure-time activity of people aged 65 years or older in the United States (Yusuf et al., 1996). In our previous research (Park et al., 2008), gardening was determined to offer moderate-intensity PA and thus has the possibility of offering the health benefits of PA for older adults. Gardening has been associated with improved physical and psychosocial health outcomes such as lower total cholesterol, lower blood pressure, lower mortality, psychological well-being, and social integration (Armstrong, 2000; Walsh et al., 2001). Turner et al. (2002) reported that gardening is an activity that is expected to influence whole body BMD because it includes weightbearing motions such as pushing a mower, digging holes, pulling weeds, carrying soil, and so on, and because it uses the whole body. Yard work and weight training were strong and positive predictors for BMD rather than other PAs such as jogging, swimming, calisthenics, bicycling, aerobic, walking, and dancing (Turner et al., 2002). Reynolds (1999) reported that gardening improved grip strength of participants after 6 months and cardiovascular fitness was expected because gardening activities elevated heart rate. In another study, Reynolds (2002) reported improved mental health and depression of participants through gardening after 3 months.

Although there is some evidence of the positive health benefits from gardening as a form of PA, there is limited research reported that has specifically studied gardening for health in older populations. Therefore, the purpose of this study was to investigate the physical and psychological health conditions (overall health conditions, hand function, and BMD) and the leisure-time activities, particularly PAs, of older gardeners and nongardeners for differences.

\section{Materials and Methods}

Subjects. Subjects were recruited from the community of Manhattan, KS. Recruitment was done in person at locations known to be frequented by older adults in Manhattan, KS, such as a senior center, coffee shops, restaurants, and churches. The researchers also recruited from garden clubs, a community garden group, exercise classes, a reading group, and an art group. In an orientation, the experimental procedures were explained, written informed consent was obtained, and a demographic information questionnaire was completed by the subjects. The demographic questionnaire was developed and included questions on age, gender, race, education, marital status, employment status, and annual income. A total of 53 subjects, aged 58 to 86 years old, participated in the study.

Health assessments. A trained specialist conducted the health assessments of the subjects in Oct. 2006. Height and weight were measured with a wall stadiometer (Seca 216 Stadiometers; Seca, Brooklyn, NY) and electronic balance (Ohaus ES200L; Ohaus, Pine Brook, NJ) without shoes. Body mass index [mass $(\mathrm{kg}) /$ height $\left.(\mathrm{m})^{2}\right]$ was calculated. Percent body fat was measured by dualenergy x-ray absorptiometry (Prodigy v6.8; GE Lunar, Milwaukee, WI).

To determine the physical and mental health conditions of the subjects, the ShortForm 36 Health Survey (SF-36) was used. The SF-36 is a 36 -item self-rated survey that measures eight domains of health: physical 
functioning, role limitations resulting from physical health, bodily pain, general health perceptions, vitality, social functioning, role limitations resulting from emotional problems, and mental health. It yields scale scores for each of these eight health domains and two summary measures of physical and mental health: the physical component summary and mental component summary. The reliability of the eight scales and two summary measures has been estimated using both internal consistency and test-retest methods. Published reliability statistics have exceeded the minimum standard of 0.70 recommended for measures used in group comparisons in more than 25 studies (Tsai et al., 1997); most have exceeded 0.80 (McHorney et al., 1994; Ware et al., 1993). Reliability estimates for physical and mental summary scores usually exceed 0.90 (Ware et al., 1994). Studies to date have reported content, concurrent, criterion, construct, and predictive evidence of validity (Ware, 2000).

Hand function (hand strength and pinch force) was determined by a hydraulic hand dynamometer and a pinch gauge (JAMAR Dynamometers 5030J1 and 7498-05; Sammons Preston, Chicago, IL). Subjects were tested three times on each hand and were asked to indicate their dominant hand.

To determine the bone density of the subjects, BMD $\left(\mathrm{g} \cdot \mathrm{cm}^{-2}\right)$ of the spine and hip was measured by a certified technician using dual-energy x-ray absorptiometry (Prodigy v6.8; GE Lunar).

Leisure-time physical activities of older adults. The Community Healthy Activities Model Program for Seniors (CHAMPS) questionnaire for older adults was used to measure leisure-time PAs. The questionnaire lists many light- and moderate-intensity PAs. Subjects are asked to indicate their frequency and duration in doing these PAs during a typical week during the previous 4 weeks. Frequency and caloric expenditure for moderate-intensity activities [metabolic equivalent (MET) values above 3.0 and below 6.0 such as brisk walking, swimming, cycling, or dancing] and for all activities (i.e., light such as watering lawn or garden, fishing, or cooking and moderate intensity) were calculated (Harada et al., 2001; Stewart et al., 1997, 2001). The PAs in this questionnaire were classified as moderate-intensity PA and lightintensity PA (below 3.0 METs) based on the values reported by Ainsworth and colleagues (Ainsworth et al., 1993). Those not reported by Ainsworth et al. (1993) were classified by interpolating values of similar activities (e.g., water exercises' MET value was drawn from water aerobics and water calisthenics) (Stewart et al., 2001). This questionnaire has been shown to be reliable and valid in estimating frequency per week of all PAs and calories expended per week in all PAs (Stewart et al., 2001).

Exercise intensity and time spent gardening were calculated based on the CHAMPS questionnaire responses to questions on gardening. Subjects were then classified as active gardeners, gardeners, or nongardeners to determine the health effects of gardening as a form of PA: active gardeners $(n=11)$ met or exceeded the CDC's PA recommendation by gardening at moderate intensity for more than 150 min per week; gardeners $(n=14)$ did not meet the CDC's PA recommendation by gardening but did garden for 120 to 150 min per week at both low and moderate intensity; and nongardeners did no gardening or little gardening at low intensity $(\mathrm{n}=28)$. By separating gardeners that met the PA recommendation through gardening from gardeners that did not, we were able to determine the effects of gardening as a moderate-intensity PA.

Data analysis. Analysis of variance was performed by the Statistical Analysis System (SAS Version 9 for Windows; SAS Institute Inc., Cary, NC). Fisher's least significant difference test was used to compare means at $P=0.05$ for health assessments and caloric expenditure and frequency of leisure-time PAs. PROC GLM and $\chi^{2}$ tests were used to

Table 1. Demographic information of 53 participants in a study to compare the physical and psychological health of active gardeners, gardeners, and nongardeners.

\begin{tabular}{|c|c|c|c|c|}
\hline Variable & $\begin{array}{l}\text { Active gardeners }{ }^{2} \\
\quad(\mathrm{~N}=11)\end{array}$ & $\begin{array}{l}\text { Gardeners }^{y} \\
(\mathrm{~N}=14)\end{array}$ & $\begin{array}{l}\text { Nongardeners }^{\mathrm{x}} \\
\quad(\mathrm{N}=28)\end{array}$ & $P$ value ${ }^{\mathrm{w}}$ \\
\hline & & Mean (SD) & & \\
\hline Age & $73(7)$ & $71(6)$ & $72(9)$ & $0.89 \mathrm{NS}$ \\
\hline Height $(\mathrm{cm})$ & $165.4(7.2)$ & $164.8(7.0)$ & $160.1(8.4)$ & $0.20 \mathrm{NS}$ \\
\hline Body weight (kg) & $75(15.6)$ & 82.7 (12.4) & $68.7(13.2)$ & $0.33 \mathrm{NS}$ \\
\hline Body mass index & $27.0(4.8)$ & $29.4(4.6)$ & $26.5(4.5)$ & $0.17 \mathrm{NS}$ \\
\hline Percent body fat & $35.1(10)$ & $\begin{array}{c}42.9(8.5) \\
\text { Percentage (\%) }\end{array}$ & $38.7(7.7)$ & $0.08 \mathrm{NS}$ \\
\hline \multicolumn{5}{|l|}{ Gender } \\
\hline Male & 54.5 & 35.7 & 28.6 & $0.31 \mathrm{NS}$ \\
\hline Female & 45.5 & 64.3 & 71.4 & \\
\hline \multicolumn{5}{|l|}{ Race } \\
\hline White & 90.9 & 100 & 75 & $0.14 \mathrm{Ns}$ \\
\hline Asian & 9.1 & 0 & 25 & \\
\hline \multicolumn{5}{|l|}{ Education ${ }^{v}$} \\
\hline High school graduate & 90.9 & 100 & 85.7 & $0.45 \mathrm{NS}$ \\
\hline $\begin{array}{l}\text { 2-year postsecondary } \\
\text { education or less }\end{array}$ & 18.2 & 35.7 & 28.6 & $0.63 \mathrm{NS}$ \\
\hline $\begin{array}{l}\text { 4-year postsecondary } \\
\text { education or less }\end{array}$ & 100 & 64.3 & 67.9 & \\
\hline No response & 0 & 0 & 3.6 & \\
\hline \multicolumn{5}{|l|}{ Marital status } \\
\hline Single $^{\mathrm{u}}$ & 36.4 & 26.8 & 35.7 & $0.88 \mathrm{NS}$ \\
\hline With partner ${ }^{t}$ & 63.6 & 71.4 & 64.3 & \\
\hline \multicolumn{5}{|l|}{ Employment status } \\
\hline Retired & 72.7 & 78.6 & 64.3 & $0.44 \mathrm{NS}$ \\
\hline Full-time & 9.1 & 7.1 & 25 & \\
\hline Part-time & 9.1 & 0 & 3.6 & \\
\hline Homemaker & 0 & 14.3 & 3.6 & \\
\hline Disability & 9.1 & 0 & 3.6 & \\
\hline \multicolumn{5}{|l|}{ Annual income } \\
\hline Less than $\$ 40,000$ & 18.2 & 50 & 32.1 & $0.22 \mathrm{NS}$ \\
\hline$\$ 40,000$ to 59,999 & 27.3 & 7.1 & 25 & \\
\hline$\$ 60,000$ to 80,000 & 9.1 & 14.3 & 21.4 & \\
\hline More than $\$ 80,000$ & 45.5 & 14.3 & 7.1 & \\
\hline No answer & 0 & 14.3 & 14.4 & \\
\hline
\end{tabular}

${ }^{z}$ Active gardeners met or exceeded the Centers for Disease Control and Prevention's (CDC) physical activity (PA) recommendation by gardening at moderate intensity for more than 150 min per week.

${ }^{y}$ Gardeners did not meet the CDC's PA recommendation by gardening but did garden for 120 to $150 \mathrm{~min}$ per week at both low and moderate intensity.

${ }^{\mathrm{x}}$ Nongardeners did no gardening or little gardening at low intensity.

wPROC GLM was used to compare means at $P=0.05$ for age, height, body weight, body mass index, and percent body fat. Chi square was used to compare values at $P=0.05$ for the remaining variables.

"The percentage sum for education in the active gardeners group is over $100 \%$ because subjects could mark "all that apply."

"Single $=$ never married, divorced, separated, or widowed.

${ }^{\mathrm{t}}$ With partner $=$ married or having a partner.

NS $=$ No significant difference by PROC GLM and $\chi^{2}$ test at $P=0.05$. 
and Related Bone Disease, National Resource Center, 2006). In practice, an individual T-score is used for the diagnosis of osteoporosis, whereas a Z-score is useful in determining whether there may be an underlying disease or condition that is causing bone loss.

\section{Results}

Demographic information. There were no significant differences among the three groups across all demographic variables (Table 1).

Table 2. Physical activity measures of active gardeners, gardeners, and nongardeners based on the CHAMPS $^{z}$ questionnaire to compare the physical and psychological health of active gardeners, gardeners, and nongardeners.

\begin{tabular}{|c|c|c|c|c|}
\hline Measure & $\begin{array}{l}\text { Active gardeners }{ }^{\mathrm{y}} \\
\qquad(\mathrm{N}=11)\end{array}$ & $\begin{array}{l}\text { Gardeners }^{x} \\
(\mathrm{~N}=14)\end{array}$ & $\begin{array}{l}\text { Nongardeners }^{\mathrm{w}} \\
\quad(\mathrm{N}=28)\end{array}$ & $P$ value \\
\hline \multicolumn{5}{|c|}{ Moderate and greater intensity measures ${ }^{v}$, mean $(\mathrm{SE})$} \\
\hline $\begin{array}{l}\text { Caloric expenditure } \\
\text { per week in at least } \\
\text { moderate-intensity physical } \\
\text { activities (MET } 3.0 \text { or greater) }\end{array}$ & $4,000(795)$ & $2,385(705)$ & $2,632(498)$ & $0.27 \mathrm{NS}$ \\
\hline $\begin{array}{l}\text { Frequency per week in at } \\
\text { least moderate-intensity } \\
\text { physical activities (MET } 3.0 \text { or greater) }\end{array}$ & $11(3)$ & $10(2)$ & $9(2)$ & $0.82 \mathrm{NS}$ \\
\hline \multicolumn{5}{|c|}{ All activities measures, mean (SE) } \\
\hline $\begin{array}{l}\text { Caloric expenditure } \\
\text { per week in all listed } \\
\text { physical activities }\end{array}$ & $5,834(1032)$ & $4,152(915)$ & $4,441(647)$ & $0.43 \mathrm{NS}$ \\
\hline $\begin{array}{l}\text { Frequency per week in all } \\
\text { listed physical activities }\end{array}$ & $22(4)$ & $26(4)$ & $22(3)$ & $0.70 \mathrm{NS}$ \\
\hline
\end{tabular}

${ }^{\mathrm{z}}$ Community Healthy Activities Model Program for Seniors.

${ }^{y}$ Active gardeners met or exceeded the Centers for Disease Control and Prevention's (CDC) physical activity (PA) recommendation by gardening at moderate intensity for more than 150 min per week.

${ }^{x}$ Gardeners did not meet the CDC's PA recommendation by gardening but did garden for 120 to $150 \mathrm{~min}$ per week at both low and moderate intensity.

wNongardeners did no gardening or little gardening at low intensity.

${ }^{\mathrm{v}}$ CHAMPS: Measuring caloric expenditure (Kcal/week) and frequency of leisure-time PAs in older adults. The PAs were classified as moderate-intensity PA [above 3.0 metabolic equivalents (METs) and below 6.0 METs] and light-intensity PA (below 3.0 METs) based on the values reported by Ainsworth et al. (1993). NS $=$ No significant difference by least significant difference test at $P=0.05$. among the groups (Table 3). Therefore, any difference in health outcomes may be explained through the gardening activity.

Health assessments. Active gardeners reported higher physical function, bodily pain (higher score indicates lower pain), and physical summary scores (Table 4). There were no differences in mental health among the three groups (Table 4), but all groups had scores higher than the U.S. general population (mean $\pm \mathrm{SD}, 50 \pm 10$ ).

There was no difference in BMD of spine and dual femur among the groups, but all participants had higher values than the standard value for their age (Table 5). Because hand function abilities are not influenced by exercise intensity, intensity of gardening was not used in classifying the subjects as was done previously. To analyze hand function abilities, subjects were classified as gardeners (gardening more than $120 \mathrm{~min}$ at both low and moderate intensity) or nongardeners (gardening less than $120 \mathrm{~min}$ at low intensity). Gardeners had significantly higher hand function abilities than nongardeners in their hand strength and pinch force $(P<0.05)$ (Table 6).

\section{Discussion}

Healthy active, older adults who participated in gardening enough to meet the PA recommendation of 30 min moderate-intensity PA on 5 or more days of the week had higher values in three of the physical domains of the SF-36 (physical function, bodily pain, and physical summary) and better hand function ability than those who were also active but did less gardening.

Physical function and bodily pain were positively associated with gardening in this

Table 3. Kinds and energy expenditure (Kcal/week) of leisure-time physical activities in CHAMPS questionnaire performed by the subjects to compare the physical and psychological health of active gardeners, gardeners, and nongardeners.

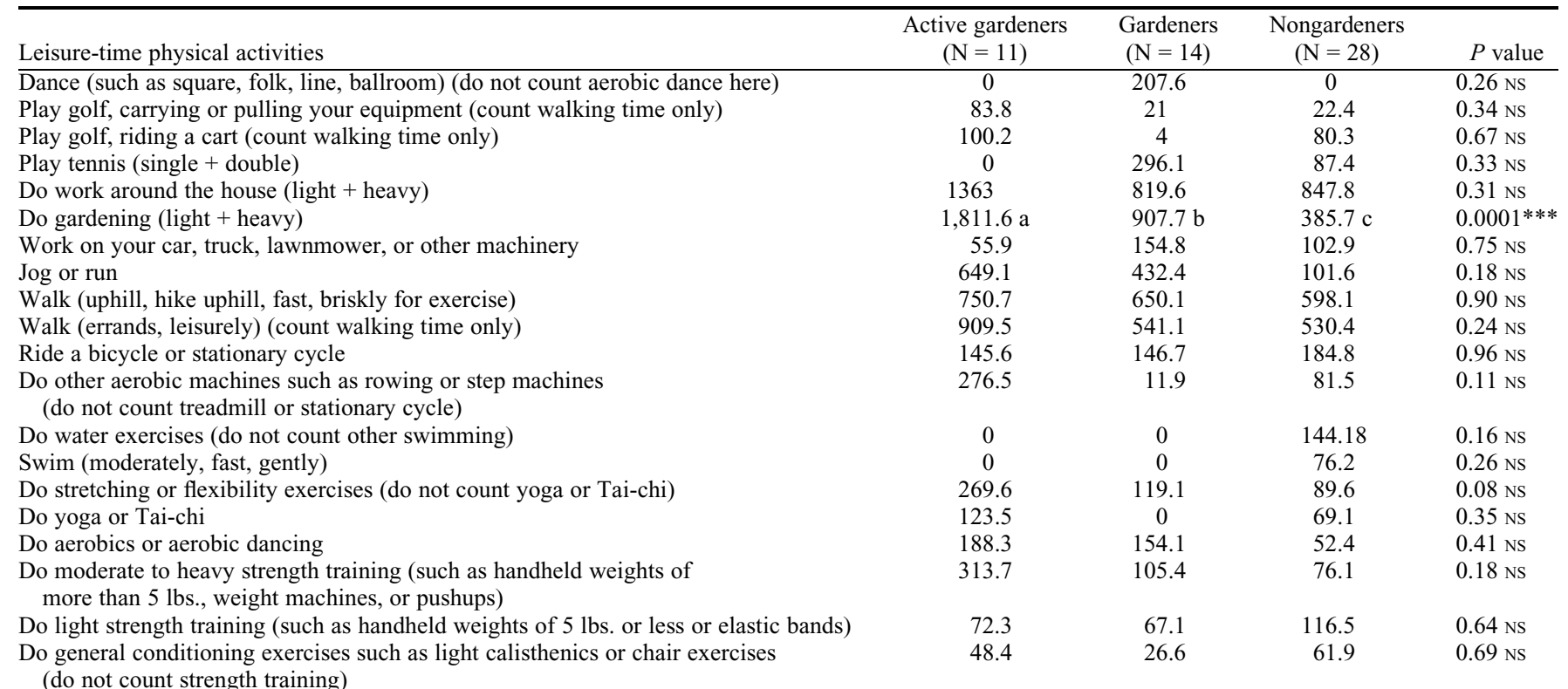

$\mathrm{a}, \mathrm{b}, \mathrm{c}=$ sharing at least one common letter are not significantly different by least significant difference test at $P=0.05$.

${ }_{* * * *} P<0.001$.

NS $=$ No significantly difference by Least Significant Difference (LSD) test at $P=0.05$. 
Table 4. Health conditions of active gardeners, gardeners, and nongardeners based on the Short-Form 36 Health Survey.

\begin{tabular}{lcccc}
\hline Component & $\begin{array}{c}\text { Active gardeners }^{\mathrm{y}} \\
(\mathrm{N}=11)\end{array}$ & $\begin{array}{c}\text { Gardeners }^{\mathrm{x}} \\
(\mathrm{N}=14)\end{array}$ & $\begin{array}{c}\text { Nongardeners }^{\mathrm{w}} \\
(\mathrm{N}=28)\end{array}$ & $P$ value \\
\hline $\begin{array}{l}\text { Physical function } \\
\text { Role limitations resulting }\end{array}$ & $54.1^{\mathrm{v}} \mathrm{a}$ & $48.9 \mathrm{~b}$ & $48.4 \mathrm{~b}$ & $0.05^{*}$ \\
$\quad$ from physical health & 53.7 & 44.3 & 48.7 & $0.06 \mathrm{NS}$ \\
Bodily pain & $56.1 \mathrm{a}$ & $44.1 \mathrm{~b}$ & $49.0 \mathrm{~b}$ & $0.01^{* *}$ \\
General health & 54.6 & 51 & 50.1 & $0.26 \mathrm{NS}$ \\
Vitality & 58.3 & 50.6 & 54.9 & $0.08 \mathrm{NS}$ \\
Social function & 55.7 & 53.3 & 53.8 & $0.69 \mathrm{NS}$ \\
Role limitations resulting & 50.6 & 48.6 & 52.0 & $0.50 \mathrm{NS}$ \\
$\quad$ from emotional problems & & & & \\
Mental health & 57.3 & 52.6 & 53.3 & $0.16 \mathrm{NS}$ \\
Physical summary & $54.6 \mathrm{a}$ & $45.6 \mathrm{~b}$ & $47.6 \mathrm{~b}$ & $0.01^{* *}$ \\
Mental summary & 55.2 & 53.2 & 55.3 & $0.65 \mathrm{NS}$ \\
\hline Z & & &
\end{tabular}

${ }^{\mathrm{z}} \mathrm{SF}-36=$ The Short Form 36 Health Survey which consists of eight scales and two summary component measures (Ware et al., 1993).

${ }^{y}$ Active gardeners met or exceeded the Centers for Disease Control and Prevention's (CDC) physical activity (PA) recommendation by gardening at moderate intensity for more than $150 \mathrm{~min}$ per week.

${ }^{\mathrm{x}}$ Gardeners did not meet the CDC's PA recommendation by gardening but did garden for 120 to 150 min per week at both low and moderate intensity.

"Nongardeners did no gardening or little gardening at low intensity.

"Norm-based scoring transformed to have a mean of 50 and a standard deviation of 10 from the 1998 U.S. general population. A scale score below 50 means below average (Ware, 2000).

$\mathrm{a}, \mathrm{b}=$ sharing at least one common letter are not significantly different by least significant difference test at $\alpha=0.05$.

${ }^{*} P \leq 0.05$

${ }^{* *} P \leq 0.01$.

NS $=$ No significant difference by least significant difference test at $P=0.05$.
Improved hand strength through gardening was also reported by Reynolds (1999). Gardening tasks can improve muscle coordination and train unused muscles in hands because many of the tasks require grasping, releasing, and flexion of the thumb and forefinger (Relf, 1973). Therefore, gardening may be used as a therapy activity for hand function ability.

All subjects had good physical and mental health based on the SF-36 results and when compared with the U.S. general population of their cohort (Ware, 2000) and were very physically active as indicated by the CHAMPS results. This supports the evidence that an active lifestyle provides physical and mental health benefits (Glass et al., 1999; Takano et al., 2002). Although all the subjects were healthy and active, the active gardeners had better physical health and hand strength and the only distinction for this group was they gardened.

This study did not show the distinct benefits of improved BMD through gardening as reported by Turner et al. (2002). The BMD values of all participants in this study were over standard values for their ages. A possible explanation is that all the subjects in

Table 5. Comparisons of bone mineral density (BMD) of active gardeners, gardeners, and nongardeners.

\begin{tabular}{|c|c|c|c|c|c|c|c|c|}
\hline & BMD & \multicolumn{2}{|c|}{$\begin{array}{l}\text { Active gardeners }{ }^{\mathrm{z}} \\
\quad(\mathrm{N}=11)\end{array}$} & \multicolumn{2}{|c|}{$\begin{array}{l}\text { Gardeners }^{y} \\
(\mathrm{~N}=14)\end{array}$} & \multicolumn{2}{|c|}{$\begin{array}{c}\text { Nongardeners }^{\mathrm{x}} \\
(\mathrm{N}=28)\end{array}$} & $P$ value \\
\hline \multirow[t]{2}{*}{$\overline{\text { Hip }}$} & $\operatorname{BMD}\left(\mathrm{g} \cdot \mathrm{cm}^{-2}\right)$ & $0.96(0.2)$ & $0.6-1.2$ & $0.96(0.1)$ & $0.8-1.3$ & $0.92(0.1)$ & $0.6-1.3$ & $0.63 \mathrm{NS}$ \\
\hline & Age-adjusted Z-scorev & 0.41 & $-2.1-1.7$ & $0.27(1.0)$ & $-1.2-2.5$ & $0.42(0.9)$ & $-1.1-2.2$ & $0.89 \mathrm{NS}$ \\
\hline \multirow[t]{3}{*}{ Spine } & $\operatorname{BMD}\left(\mathrm{g} \cdot \mathrm{cm}^{-2}\right)$ & $1.11(0.2)$ & $0.7-1.4$ & $1.24(0.3)$ & $0.9-1.9$ & $1.13(0.2)$ & $0.7-1.7$ & $0.23 \mathrm{NS}$ \\
\hline & Young-adult T-score & $-0.80(1.7)$ & $-3.8-1.7$ & $0.37(2.1)$ & $-2.5-5.3$ & $-0.51(1.6)$ & $-3.6-3.8$ & $0.21 \mathrm{NS}$ \\
\hline & Age-adjusted Z-score & $0.21(1.4)$ & $-2.5-2.3$ & $1.24(2.1)$ & $-1.4-5.9$ & $0.78(1.6)$ & $-2.1-4.7$ & $0.34 \mathrm{NS}$ \\
\hline
\end{tabular}

${ }^{2}$ Active gardeners met or exceeded the Centers for Disease Control and Prevention's (CDC) physical activity (PA) recommendation by gardening at moderate intensity for more than 150 min per week.

${ }^{y}$ Gardeners did not meet the CDC's PA recommendation by gardening but did garden for 120 to 150 min per week at both low and moderate intensity.

${ }^{x}$ Nongardeners did no gardening or little gardening at low intensity.

"T-score is given by comparing the ideal or peak BMD of a healthy 30 -year-old adult with the subjects' BMD. A score of 0 indicates the BMD is same to the norm for a healthy young adult. A T-score of -2.5 or lower means the person has osteoporosis.

'Z-score is given to compare the BMD value with a typical individual age, which is matched to specific age.

NS $=$ No significant difference by least significant difference test at $P=0.05$.

Table 6. Comparisons of hand function ability of active gardeners + gardeners and nongardeners.

\begin{tabular}{|c|c|c|c|c|}
\hline Hand function & Hand & $\begin{array}{l}\text { Active gardeners }+ \\
\text { gardeners }^{\mathrm{z}}(\mathrm{N}=25)\end{array}$ & $\begin{array}{l}\text { Nongardeners }^{\mathrm{y}} \\
(\mathrm{N}=28)\end{array}$ & $P$ value \\
\hline \multirow[t]{3}{*}{ Strength } & Dominant & $30.1 \mathrm{a}$ & $25.1 \mathrm{~b}$ & $0.04^{*}$ \\
\hline & Left & $28.6 \mathrm{a}$ & $22.9 \mathrm{~b}$ & $0.02 *$ \\
\hline & Right & $30.2 \mathrm{a}$ & $24.9 \mathrm{~b}$ & $0.03 *$ \\
\hline \multirow[t]{3}{*}{ Pinch force } & Dominant & $6.2 \mathrm{a}$ & $4.7 \mathrm{~b}$ & $0.00 * *$ \\
\hline & Left & $5.9 \mathrm{a}$ & $4.3 \mathrm{~b}$ & $0.00 * *$ \\
\hline & Right & $6.2 \mathrm{a}$ & $4.6 \mathrm{~b}$ & $0.01 * *$ \\
\hline
\end{tabular}

${ }^{\mathrm{z}}$ Active gardeners and gardeners were combined. Because hand function abilities are not strongly influenced by exercise intensity, intensity of gardening was not used in classifying the subjects as was done previously. Active gardeners + gardeners did gardening more than $120 \mathrm{~min}$ at both low and moderate intensity.

${ }^{y}$ Nongardeners did gardening less than $120 \mathrm{~min}$ at low intensity.

$\mathrm{a}, \mathrm{b}=$ sharing at least one common letter are not significantly different by least significant difference test at $\alpha=0.05$.

${ }^{*} P<0.05$

${ }^{* * *} P \leq 0.01$.

study. Basen-Engquist et al. (2006) reported that moderate activity in daily routines of cancer survivors led to positive effects on bodily pain as reported in the SF-36. Most gardening tasks work the muscles of the body (Restuccio, 1992) so physical function ability can be improved through improved muscle strength. this study had healthy BMD because of their very physically active lifestyle as determined from the CHAMPS results (ACSM, 2004). Also, most of the older subjects showed high education attainment (Table 1) and education is assumed to be a contributor to bone health. A nutrition program, including a bone health curriculum, reduced the risk factors related to osteoporosis (Cheong et al., 2003). Cankurtaran et al. (2005) reported that low educational attainment is a risk factor for osteoporosis.

The results of this study support the need for continued research with a larger sample size. Additionally, research should determine various health benefits of gardening in older adults by treating gardening as an exercise intervention.

\section{Literature Cited}

Ainsworth, B.E., W.L. Haskell, A.S. Leon, D.R. Jacobs, H.J. Montoye, J.F. Sallis, and R.S. Paffenbarger. 1993. Compendium of physical 
activities: Classification of energy costs of human physical activities. Med. Sci. Sports Exerc. 25:71-80.

American College of Sports Medicine. 1993. Physical activity, physical fitness, and hypertension. Med. Sci. Sports Exerc. 10:i-x.

American College of Sports Medicine. 1998. Exercise and physical activity for older adults. Med. Sci. Sports Exerc. 30:992-1008.

American College of Sports Medicine. 2004. Physical activity and bone health. Med. Sci. Sports Exerc. 36:1985-1996.

Armstrong, D. 2000. A survey of community gardens in upstate New York: Implications for health promotion and community development. Health Place 6:319-327.

Basen-Engquist, K., C.L. Talyor, C. Rosenblum, M.A. Smith, E.H. Shinn, A. Greisinger, X. Gregg, P. Massey, V. Valero, and E. Rivera. 2006. Randomized pilot test of a lifestyle physical activity intervention for breast cancer survivors. Patient Educ. Couns. 64:225-234.

Cankurtaran, M., B.B. Yavuz, M. Halil, N. Dagli, and S. Ariogul. 2005. General characteristics, clinical features and related factors of osteoporosis in a group of elderly Turkish men. Aging Clin. Expt. Res. 17:108-115.

Cheong, J.M.K., M.A. Johnson, R.D. Lewis, J.G. Fischer, and J.T. Johnson. 2003. Reduction in modifiable osteoporosis-related risk factors among adults in the older Americans nutrition program. Family Econ. Nutr. Rev. 15:83-91.

DiPietro, L. 2001. Physical activity in aging: Changes in patterns and their relationship to health and function. J. Gerontology Ser. A: Biol. Sci. Medical Sci. 56A:13-22.

Galloway, M.T. and P. Jokl. 2000. Aging successfully: The importance of physical activity in maintaining health and function. J. Amer. Acad. Orthop. Surg. 8:37-44.

Glass, T.A., C.M. deLeon, R.A. Marottoli, and L.F. Berkman. 1999. Population based study of social and productive activities as predictors of survival among elderly Americans. BMJ 319:478-483.

Harada, N.D., V. Chiu, and A.L. Stewart. 2001. An evaluation of three self-report physical activity instruments for older adults. Med. Sci. Sports Exerc. 33:962-970.

Hui, E.K. and L.Z. Rubenstein. 2006. Promoting physical activity and exercise in older adults. J. Amer. Medical Directors Assn. 7:310-314.
Lee, I., R.S. Paffenbarger, and C. Hsieh. 1991. Physical activity and risk of developing colorectal cancer among college alumni. J. Natl. Cancer Inst. 83:1324-1329.

McHorney, C.A., J.E. Ware, J.F.R. Lu, and C.D. Sherbourne. 1994. The MOS 36-Item Short Form Health Survey (SF-36®): III. Tests of data quality, scaling assumptions and reliability across diverse patient groups. Med. Care 32:40-66.

National Institutes of Health Osteoporosis and Related Bone Disease, National Resource Center. 2006. Bone mass measurement: What the numbers mean. June 2006. <http:// www.niams.nih.gov/Health_Info/bone/Bone Health/bone_mass_measure.asp $>$.

Nelson, M.E., W.J. Rejeski, S.N. Blair, P.W Duncan, J.O. Judge, A.C. King, C.A. Macera, and C. Castaneda-Sceppa. 2007. Physical activity and public health in older adults: Recommendation from the American College of Sports Medicine and the American Heart Association. Med. Sci. Sports Exerc. 39:14351445.

Park, S., C.A. Shoemaker, and M.D. Haub. 2008. Can older gardeners meet the physical activity recommendation through gardening? HortTechnology 18:639-643.

Pate, R.R., M. Pratt, S.N. Blair, W.L. Haskell, C.A. Macera, C. Bouchard, D. Buchner, W. Ettinger, G.W. Heath, A.C. King, A. Kriska, A.S. Leon, B.H. Marcus, J. Morris, R.S. Paffenbarger, K. Patrick, M.L. Pollock, J.M. Rippe, J. Sallis, and J.H. Wilmore. 1995. A recommendation from the Centers for Disease Control and Prevention and the American College of Sports Medicine. J. Amer. Medical Assn. 273:402-407.

Powell, K.E., P.D. Thompson, C.J. Casperson, and J.S. Kendrick. 1987. Physical activity and the incidence of coronary heart disease. Annu. Rev. Public Health 8:253-287.

Relf, D. 1973. Horticulture: A therapeutic tool. J. Rehabil. 39:27-29.

Restuccio, J.P. 1992. Fitness the dynamic gardening way. Balance of Nature Publishing, Cordova, TN.

Reynolds, V. 1999. The Green Gym: An evaluation of a pilot project in Sonning Common, Oxfordshire, Report no. 8. Oxford Brookes University, Oxford, UK.

Reynolds, V. 2002. Well-being comes naturally: An evaluation of the BTCV Green Gym at
Portslade, East Sussex, Report no. 17. Oxford Brookes University, Oxford, UK.

Stewart, A.L., K.M. Mills, A.C. King, W.L. Haskell, D. Gillis, and P.L. Ritter. 2001. CHAMPS physical activity questionnaire for older adults: Outcomes for interventions. Med. Sci. Sports Exerc. 33:1126-1141.

Stewart, A.L., K.M. Mills, P.G. Sepsis, A.C. King, B.Y. McLellan, K. Roitz, and P.L. Ritter. 1997. Evaluation of CHAMPS, a physical activity promotion program for older adults. Ann. Behav. Med. 19:353-361.

Takano, T., K. Nakamura, and M. Watanabe. 2002. Urban residential environments and senior citizens' longevity in megacity areas: The importance of walkable green spaces. J. Epidemiol. Community Health 56:913-918.

Tsai, C., M.S. Bayliss, and J.E. Ware. 1997. SF-36® health survey annotated bibliography: Second edition (1988-1996). Health Assessment Lab, New England Medical Center, Boston, MA.

Turner, L.W., M.A. Bass, L. Ting, and B. Brown. 2002. Influence of yard work and weight training on bone mineral density among older U.S. women. J. Women Aging 14:139-149.

U.S. Department of Health and Human Services. 1996. Physical activity and health: A report of the surgeon general, p. 13-14. U.S. Department of Health and Human Services, Centers for Disease Control and Prevention, National Center for Chronic Disease Prevention and Health Promotion, The President's Council on Physical Fitness and Sports, Atlanta, GA.

Walsh, J.M.E., A.R. Pressman, J.A. Cauley, and W.S. Browner. 2001. Predictors of physical activity in community-dwelling elderly white women. J. Gen. Intern. Med. 16:721-727.

Ware, J.E. 2000. SF-36 health survey update. Spine 25:3130-3139.

Ware, J.E., M. Kosinski, and S.K. Keller. 1994. SF$36 \AA$ physical and mental health summary scales: A user's manual. The Health Institute, Boston, MA.

Ware, J.E., K.K. Snow, M. Kosinski, and B. Gandek. 1993. SF-36 health survey: Manual and interpretation guide. Health Institute, New England Medical Center, Boston, MA.

Yusuf, H.R., J.B. Croft, W.H. Giles, R.F. Anda, M.L. Casper, C.J. Caspersen, and D.A. Jones. 1996. Leisure-time physical activity among older adults: United States. Arch. Intern. Med. 156:1321-1326. 